\title{
Automatization of Forest Fire Detection Using Geospatial Technique
}

\author{
Shaily R. Gandhi, Tarun P. Singh \\ Symbiosis Institute of Geoinformatics, Symbiosis International University, Pune, India \\ Email: shaily.gandhi@gmail.com
}

Received 20 March 2014; revised 9 May 2014; accepted 7 June 2014

Copyright (C) 2014 by authors and Scientific Research Publishing Inc. This work is licensed under the Creative Commons Attribution International License (CC BY). http://creativecommons.org/licenses/by/4.0/

(c) (i) Open Access

\begin{abstract}
Healthy forest is the vital resource to regulate climate at a regional and global level. Forest fire has been regarded as one of the major reasons for the loss of forest and degradation of the environment. Global warming is increasing its intensity at an alarming rate. Real-time fire detection is a necessity to avoid large scale losses. Remote sensing is a quick and cheap technique for detecting and monitoring forest fires on a large scale. Advance Very Radiometer Resolution (AVHRR) has been used already for a long period for fire detection. The use of Moderate Resolution Imaging Radio Spectrometer (MODIS) for fire detection has recently preceded AVHRR and a large number of fire products are being developed. MODIS based forest fire detection and monitoring system can solve the problem of real-time forest fire monitoring. The system facilitates data acquisition, processing, reporting and feedback on the fire location information in an automated manner. It provides location information at $1 \times 1$ kilometer resolution on the active fires which are present during the satellite overpass twice a day. The users are provided with the information on SMS alert with fire location details, email notification, and online visualization of fire locations on website automatically. The whole processes are automated and provide better accuracy for fire detection.
\end{abstract}

\section{Keywords}

Geographic Information System, Remote Sensing, Forest Fires, Fire Detection, MODIS, Automated System

\section{Introduction}

Monitoring and management of forest fires is very important in tropical countries like India where 55 percent of the total forest covers are prone to fires annually causing adverse ecological, economic and social impacts. It is important to be able to have real time or near real time detection of active fires for early warning of impending 
haze and for aids in fire fighting and management. Satellite remote sensing provides a useful means of detecting regional fires. Active fires are usually detected using thermal sensors on-board remote sensing satellites by detecting the infrared radiation emitted from the fires. This procedure is commonly known as "hot spot detection". Fire Situation in the Islamic Republic of Iranhave been carried out using MODIS data (Allard, 2003).

Fire in forests and fields can have strong influences on natural resources, human health, weather and climate. This study considers the utilization of MODIS data for a system to search for fire regions in forests and fields. For the search system to be effective, the system must be able to extract the location, range and distribution of fires in forests and fields from a large scale image database quickly with high accuracy. NASA provides MOD14 (Thermal Anomalies data set: spatial resolution $1000 \mathrm{~m}$ ), however there are some cases in which forest fires cannot be correctly distinguished because of the low resolution and accuracy of the data. Although the original MODIS fire detection algorithm of (Kaufman, Justices et al., 1998) functioned reasonably well following several initial post launched reasonably following several initial post launch revisions collectively known as "version 3" (Justice, Giglio et al., 2002) the major problems detected were false detection of fire and relatively small fire was not detected. The improved detection algorithm was based on the original MODIS detection algorithm (Kaufman, Justice et al., 1998) heritage algorithm developed for the Advanced Very High Resolution Radiometer (AVHRR) and the Visible and Infrared Scanner (VIRS) (Giglio, Kendall, \& Justics, 1999). ICIMOD is one of the systems which are monitoring the forest fire in the Himalayan Range (International Centre for Integrated Mountain Development). An Agent Based Algorithm for Forest Fire Detection was one more way of detection fire pixels (Movaghati, Samadzadegan, \& Azizi, 2009).

\section{About MODIS}

MODIS stands for MODerate Resolution Imaging Spectroradiometer. The MODIS instrument is on board NASA's Earth Observing System (EOS) Terra (EOS AM) and Aqua (EOS PM) satellites. The orbit of the Terra satellite goes from north to south across the equator in the morning and Aqua passes south to north over the equator in the afternoon resulting in global coverage every 1 to 2 days (Justice, Townshend et al., 2002). The EOS satellites have a \pm 55 degree scanning pattern and orbit at $705 \mathrm{~km}$ with a $2330 \mathrm{~km}$ swath width. MODIS carries 490 detectors that are aligned in parallel rows on four separate focal planes (Visible, NIR, SWIR/MWIR, and LWIR). The MODIS instrument provides 36 spectral bands from wavelengths of $0.4 \mu \mathrm{m}$ to $14.4 \mu \mathrm{m}$ (Eric \& Vermote, 2011).

\section{Study Area}

Study Area is Pune district of Maharashtra state which lies between $17^{\circ} 5^{\prime}$ to $19^{\circ} 2^{\prime}$ North latitude and $73^{\circ} 2^{\prime}$ to $75^{\circ} 1$ ' East longitude located $560 \mathrm{~m}$ above sea level on the western margin of the Deccan plateau as shown in Figure 1. Total area of Pune district is 15,642 sq km out of which $1333 \mathrm{sq} \mathrm{km}$ is forest cover. The forest types of

Study Area Pune District

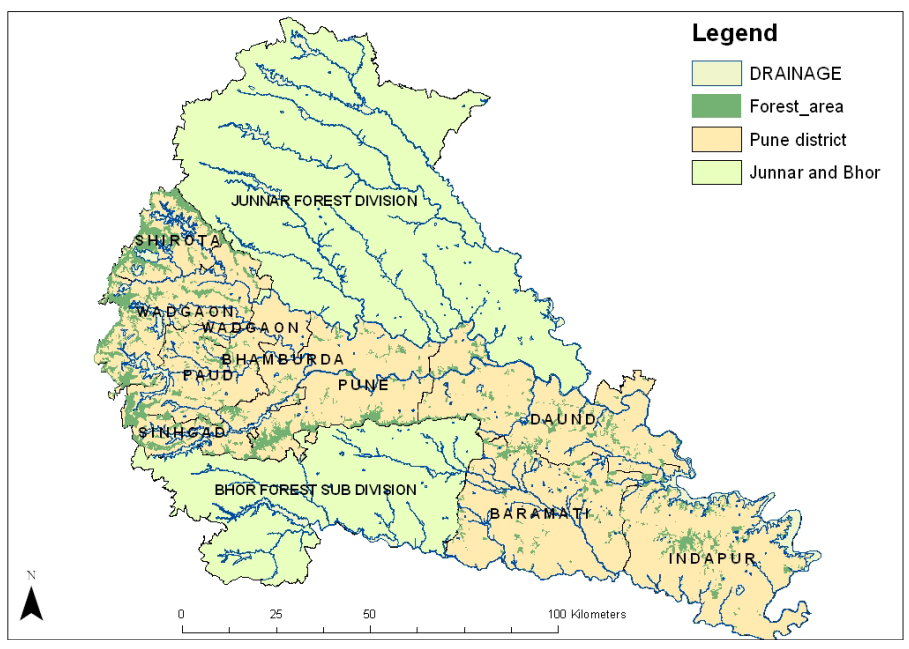

Figure 1. Study area. 
Pune can be defined as degraded forests, Open Forest and Reserved Forest, which has maximum trees of dry deciduous forest type. These dry deciduous forests are characterized by a higher proportion of teak (Tectonagrandis) and sal (Shorearobusta), which results in higher flammability. Hence these forests are more prone for the fire.

\section{Data Used}

Fire Information for Resource Management System (FIRMS) integrates remote sensing and GIS technologies to deliver global MODIS hotspot/active fire locations to natural resource managers and other stakeholders around the World. FIRMS was developed by the University of Maryland with funds from NASA. FIRMS is currently being transitioned to an operational system at the United Nations Food and Agriculture Organization (UN FAO). FIRMS is primarily aimed at supporting natural resource managers, researchers, planners and policy makers by helping them understand when and where fires occur and delivering the fire information in near real-time and in easy-to-use formats (Christopher, Louis et al., 2006). Each hotspot/active fire location represents the centre of a $1 \mathrm{~km}$ pixel (approximately) flagged as containing one or more actively burning hotspots/fires within that pixel. The hotspots/fires are detected using data from the MODIS (or Moderate Resolution Imaging Spectroradiometer) instrument, on board NASA's Aqua and Terra satellites, using a specific fire detection algorithm that makes use of the thermal band detection characteristics of the sensor. Shapefiles, text files and kml files were downloaded from FIRMS which would contain the fire information of 24 past hours, 48 hours and last 7 days. Daily nearreal time in various resolutions: 4 km, 2 km, 1 km, 500 m, and $250 \mathrm{~m}$ was also available (Zheng \& Wan, 2007).

\section{Methodology}

The following Figure 2 shows the methodology for the entire study.

\section{Algorithm Description}

The algorithm uses brightness temperatures derived from the MODIS 4- and 11-Am channels, denoted by T4 and T11, respectively. The MODIS instrument has two 4-Am channels, numbered 21 and 22, both of which are used by the detection algorithm. Channel 21 saturates at nearly $500 \mathrm{~K}$; channel 22 saturates at $331 \mathrm{~K}$. Since the low-saturation channel (22) is less noisy and has a smaller quantization error, T4 is derived from this channel whenever possible. However, when channel 22 saturates or has missing data, it is replaced with the high satura-

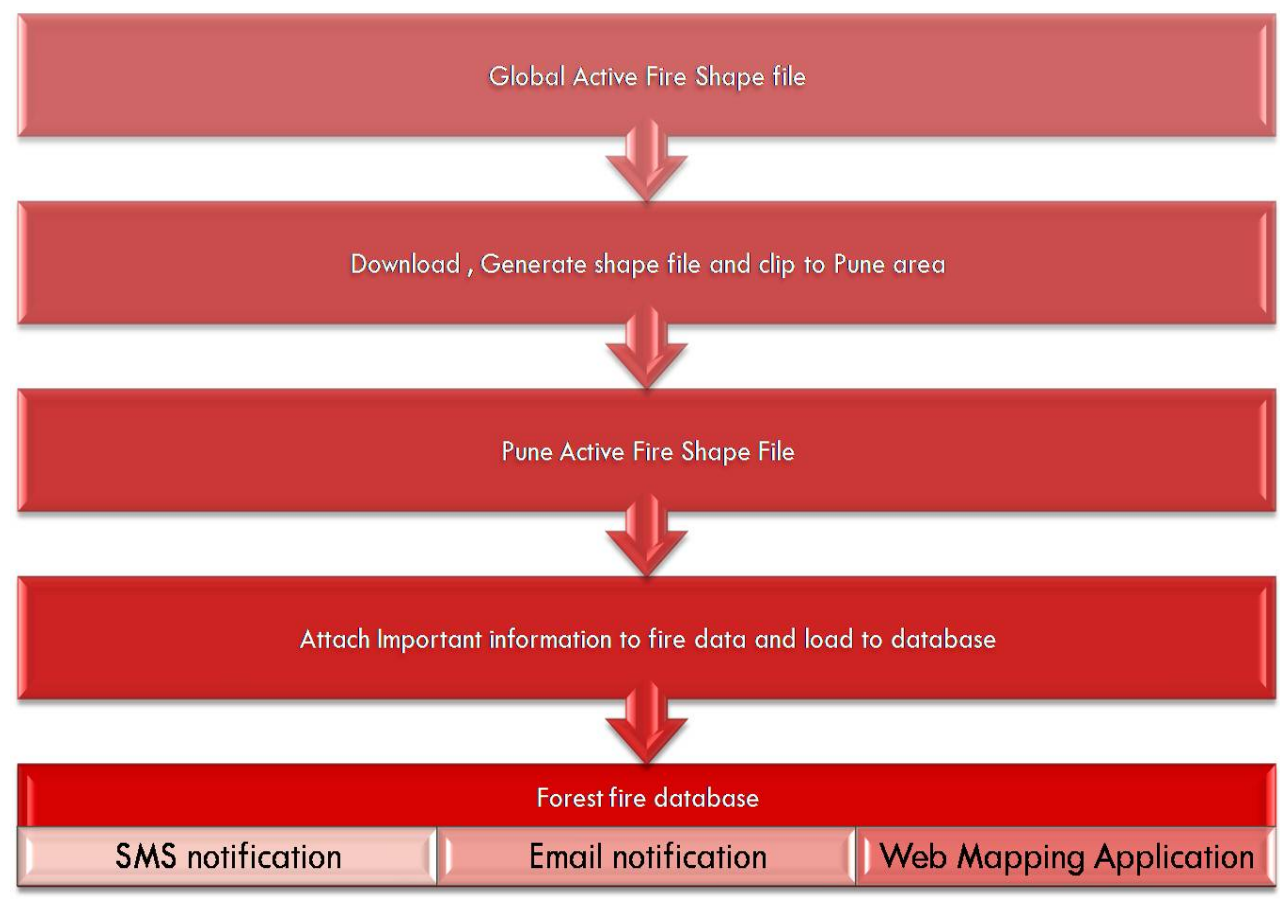

Figure 2. Methodology flow chart. 
tion channel to derive T4. T11 is computed from the 11-Am channel (channel 31), which saturates at approximately $400 \mathrm{~K}$ for the Terra MODIS and $340 \mathrm{~K}$ for the Aqua MODIS. The 12-Am channel (channel 32) is used for cloud masking; brightness temperatures for this channel are denoted by T12. The 250-m resolution red and near-infrared channels, aggregated to $1 \mathrm{~km}$, are used to reject false alarms and mask clouds. These reflectances are denoted by q0.65 and q0.86, respectively. The $500-\mathrm{m} 2.1-\mathrm{Am}$ band, also aggregated to $1 \mathrm{~km}$, is used to reject water-induced false alarms; the reflectance in this channel is denoted by q2.1 (Soo, Agnes, \& Leong, 2005). An Intelligent System for Effective Forest Fire Detection Using Spatial Data is one more way of fire detection developed (Angayarkkani \& Radhakrishnan, 2010).

\subsection{Identification of Potential Fire Pixels}

A preliminary classification is used to eliminate obvious non-fire pixels. Those pixels that remain are considered in subsequent tests (described in the next sections) to determine if they do in fact contain an active fire. A daytime pixel is identified as a potential fire pixel if T4 $>310 \mathrm{~K}, \mathrm{DT}>10 \mathrm{~K}$, and

$$
\mathrm{q} 0.86<0.3
$$

$$
\text { where } \mathrm{DT}=\mathrm{T} 4-\mathrm{T} 11
$$

(Louis, Jacques et al., 2003).

For night-time pixels, the reflective test is omitted and the T4 threshold reduced to $305 \mathrm{~K}$. Pixels failing these preliminary tests are immediately classified as non-fire pixels. There are two logical paths through which fire pixels can be identified. The first consists of a simple absolute threshold test. The second path consists of a series of contextual tests designed to identify the majority of active fire pixels that are less obvious (Louis, Jacques et al., 2003).

\subsection{Absolute Threshold Test}

The absolute threshold criterion remains identical to one employed in the original algorithm (Kaufman, Justice et al., 1998):

$$
\text { T4 > } 360 \mathrm{~K}(320 \mathrm{~K} \text { at night }) \text { and DT }>20 \mathrm{~K}(10 \mathrm{~K} \text { at night })
$$

Despite the high daytime threshold, the utility of this test hinges upon adequate sun glint rejection; otherwise, glint induced false alarms can occur.

\subsection{NDFI}

Normalized Burned Ratio (NBR) or NDFI (Normalized Difference Fire Index) was proposed for the detection of a fire in forests.

$$
\mathrm{NDFI}=(\text { Band7 }- \text { Band2 }) /(\text { Band7 }+ \text { Band2 })(-1.0<\text { NDFI }<1.0)
$$

(Nunohiro, Katayama et al., 2007).

The value of NDFI becomes large by rising temperature and decreasing chlorophyll, as when forest or field fire occurs. But the value of Band7 becomes large by the influence of rise in temperature and scatter effect of clouds. As a result, the value of NDFI shows high value by influence of thin cloud over bodies of water. Therefore we use MNDFI (Modified NDFI) as the index to search fire areas in forests and fields.

\subsection{Comparing the Algorithm-Result with "MOD14"}

MOD 12 is the science data sets for MODIS/Terra Thermal Anomalies/ Fire 5 min L2 Swath 1 km V005. It has a fire pixel table which contains 21 columns of information relevant to a fire pixel. Each column is stored as a separate Science Data Set (SDS) to accommodate limitations in the HDF format. MODIS Thermal Anomalies/ Fire products are primarily derived from MODIS 4- and 11-micrometer radiances. The fire detection strategy is based on absolute detection of a fire (when the fire strength is sufficient to detect), and on detection relative to its background (to account for variability of the surface temperature and reflection by sunlight). Numerous tests are employed to reject typical false alarm sources like sun glint or an unmasked coastline. Thus with the help of this we can check the accuracy of the algorithm developed (Jeffrey, Louis et al., 2005). 


\subsection{System Development}

A python code was developed to get the real time images from MODIS which could be used for creating automatic system (Christian, 2009). Automated process to download the MODIS active fire data from Fire Information for Resource Management System (FIRMS) in the form of Shapefiles the processing is done on the Shapefile and final output of forest fire information is sent by Short Message Service (SMS), emails and output is also shown on the website.

\section{Working of the System}

The python code written to download and process the data is set on the system time so it starts processing automatically at the given time. The steps followed by the system are to download the latest shape file from FIRMS website. Filter the result according to the area of interest and intensity of the fire. This file is added to the database and saved with date and time, which will keep a record of the past forest fire information. The shape file is updated in the mxd file format and symbology is also set. Fire Pixel is checked with in which region it falls under and information send to the respective forest staff through SMS and Email. The python code downloads the data on daily bases from the ftp of FIRMS website. Data downloaded contains information about entire south Asia. This data is clipped to the Pune region using clip function by using the python code. This code performs all the steps one by one and gives the end result. The above figure shows the first step of the code. This code is set to run automatically on system time which runs daily and all the functions are performed step by step which gives a forest fire database. After the data is update this data is merged with the forest department data which contains the information about the area monitored by the respective forest staff. Hence information about the forest fire is achieved in which contains complete information. With the help of this information SMS and Email alerts are sent to the respective people. Below Figure 3 shows SMS alert sent by the automation code which contains information "Fire has occurred at place Bhor Lat: 18.164 Long: 73.766 On Date: 2012-05-02 at time: 8:45". This information helps them to take quick actions against the disaster. Similar message are sent on Email to the authority using Gmail gateway by creating at Gmail account forestfire.pune@gmail.com which can be used to send automatic emails to respective authorities. Figure 4 shows the email message.

The final step of the automation code is to display all the output on the website. All the latitude, longitude and date information about the forest fires can also be assessed by the website and forest fire updates are updated twice a day and within 5 min after the data is downloaded. This site has been developed on Silver light platform and is published using ArcGIS server. As shown in Figure 5 it has the following functionality like it can display

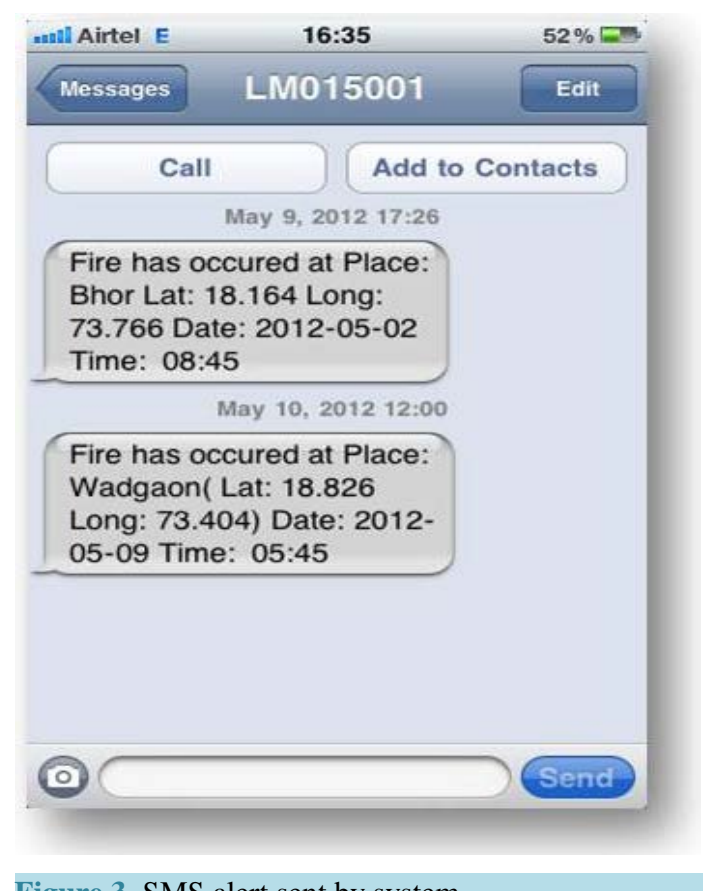

Figure 3. SMS alert sent by system. 


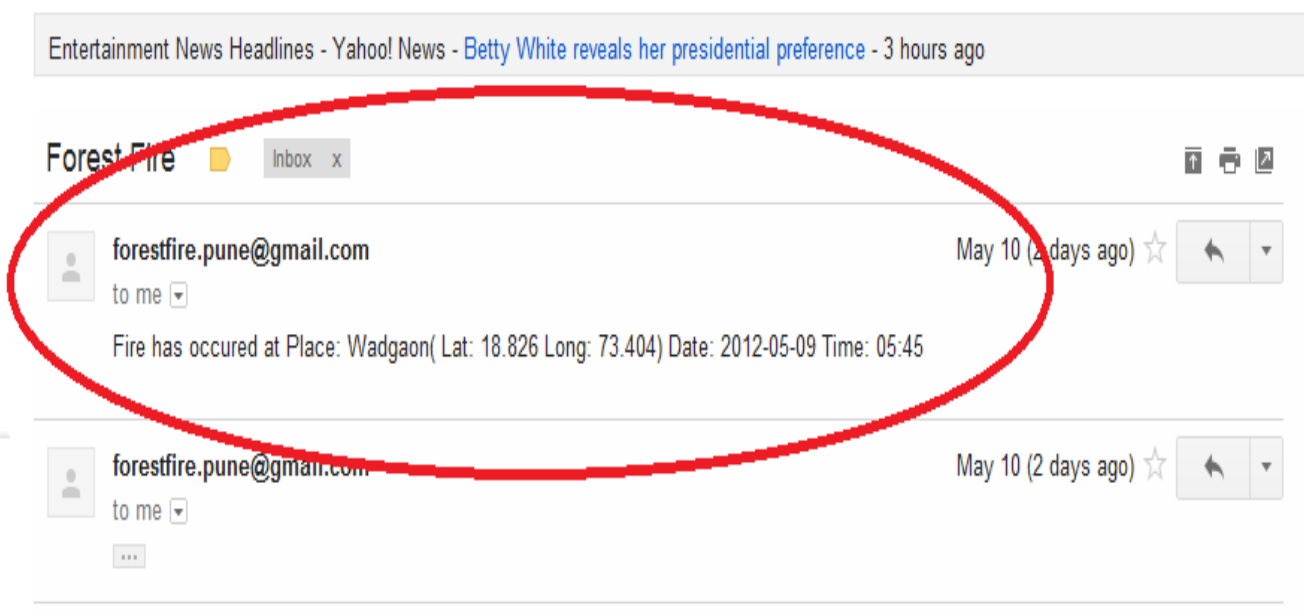

Figure 4. Emails to the officers sent by the system.

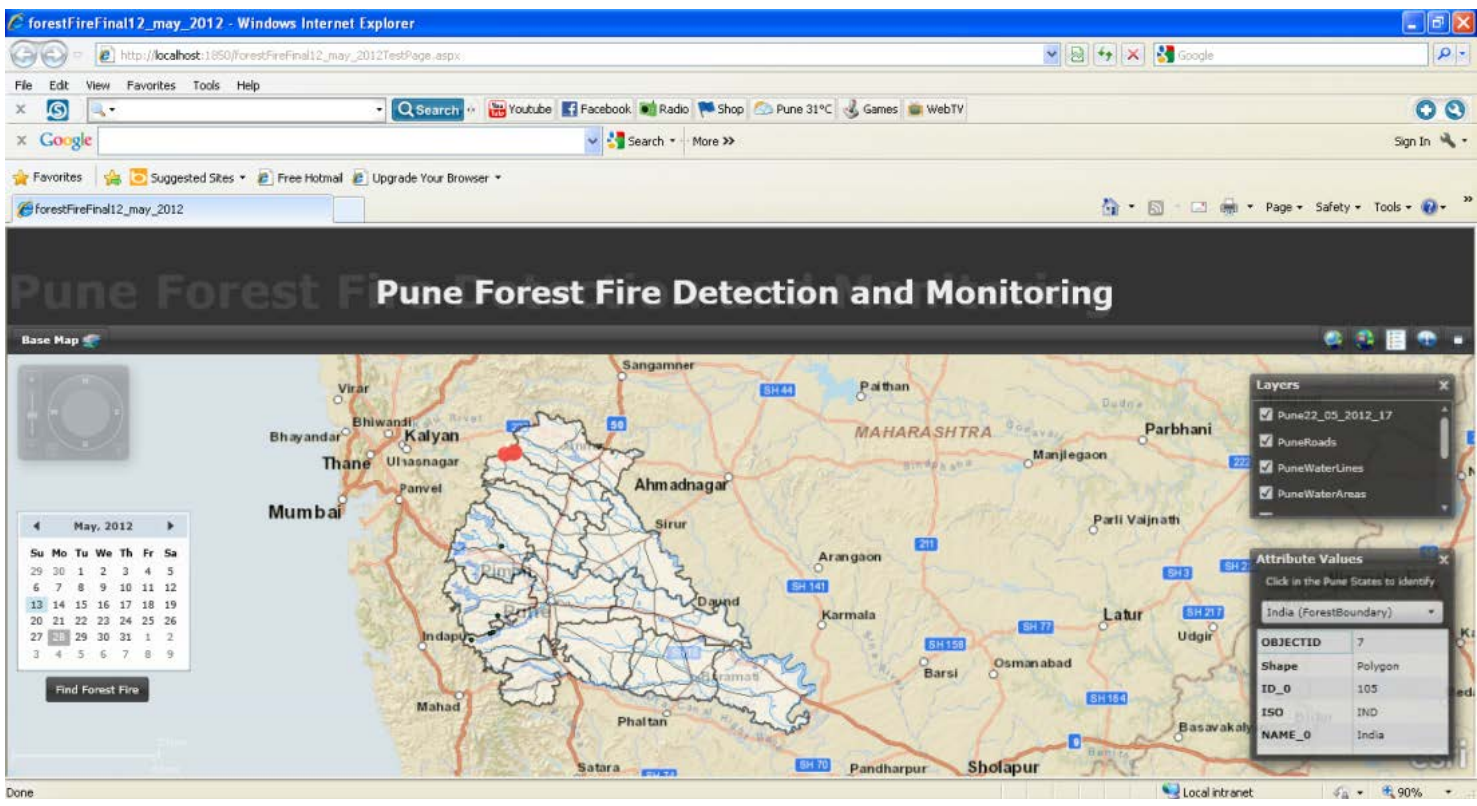

Figure 5. Information of forest fire on web.

forest fire information according to the date selected. Different base layers can be selected and layers can be turned on and off as required. Detailed information about the forest fire can be read in the attribute table by clicking on any of the fire point. Basic functions like zoom in and zoom out are also present.

\section{Ground Truth}

To check the accuracy of the FIRMS data we took the details of the forest fire hot spot and went on the site to check if there was a forest fire or not. With the evidence we found that forest fire had occurred in that location. Date: 5th April 2012 near Bimashankar area location 19¹'37.20"N, 73² $42^{\prime} 0.00^{\prime \prime E}$.

\section{Discussion}

There are few limitations of this study which need to be looked into. One of the major problems which might arise is when the link from which the data is downloaded changes to overcome this we need to change the FTP addresses in the python code. Next is we would have to manually change the location of the files and folders in the code to make it run properly without any error. Data needs to be kept updated else message will go to the 
wrong person as system will send massages to the number which is there in the system. Problem may occur in the system if net connection fails thus to keep the system working we need continues net connection. This system will detect fires which occur in an area of $500 \mathrm{~m}$ or greater as the resolution of the MODIS data is $500 \mathrm{~m}$ thus fires which occur in an area less than $500 \mathrm{~m}$ will not will be detected.

\section{Scopes of the Study}

Similar system, using appropriate shapefiles and data, has to be developed for other state of India. Furthermore, similar system can be developed for different states/regions by acquiring suitable shapefiles and data. This system is so made that changing the shapefiles and data inputs, it can be used to detect forest fire in any of the South-Asian Countries/States. The system developed in such a way that can detect forest fire in any part of the world, by making minor changes to certain links along with shapefiles and other essential data.

\section{Conclusion}

A satellite based forest fire detection and monitoring system had been developed which makes the linking of the fire information to administrative units and automatic SMS and Email alert are sent to the person in charge giving them the location with latitude and longitude information. With the help of this system the response time is decreased and the information is sent to all the people in charge at the same time. Thus this system may help to control the loss caused by the forest fire as actions against the fires can be taken as soon as the fire is detected. Moreover a database is created which contains all the information of the fires taking place in the Pune district. This can be helpful to study the past fire details. A website is developed to give fire data information to the common man, and also this can keep the people aware about the forest fires. The administrative layers and road network data are used along with the active fire points to identify the concerned administrative units and distance to the nearest road. This system will make the existing system much faster. Manual system will be converted into an automatic system. This will reduce the response so efficiency of the system will increase as well as the fires will be fighting faster causing less of damage. Future development can be done in this system to add network analysis which can tell us which route to take to fight the fire. Then we can also find the intensity of the fire which will help the offices to take the required number of resources. A decision support system can be developed which can help the officers for taking steps to fight the fire.

\section{References}

Allard, G. B. (2003). Fire Situation in the Islamic Republic of Iran. International Forest Fire News (IFFN), $28,88-91$.

Angayarkkani, K., \& Radhakrishnan, S. N. (2010). An Intelligent System for Effective Forest Fire Detection Using Spatial Data. International Journal of Computer Science and Information Security, 7, 1. www.ijcsi.org

Christian, S. P. (2009). Python: Accessing near Real-Time MODIS Images and Fire Data from NASA's Aqua and Terra Satellites.

Christopher, J., Louis, G., Luigi, B., David, R., Ivan, C., Jefferey, M., \& Yoram, K. S. N. (2006). Algorithm Technical Background Document MODIS Fire Products, Version 2.3, MODIS Fire Products. modis.gsfc.nasa.gov

Eiji, N., Kei, K., Kenneth, J. M., \& Jong Geol Park, S. N. (2007). Forest and Field Fire Search System Using MODIS Data, Paper No. 8. Journal of Advanced Computational Intelligence and Intelligent Informatics, 11. www.fujipress.jp

Eric, F., \& Vermote, S. N. (2011). MODIS Surface Reflectance User’s Guide, Version 1.3, MODIS Fire Products. http://modis-sr.ltdri.org

Giglio, L., Kendall, J. D., \& Justice, C. O. (1999). Evaluation of Global Fire Detection Algorithms Using Simulated AVHRR Infrared Data. International Journal of Remote Sensing, 20, 1947-1985. http://dx.doi.org/10.1080/014311699212290

Jeffrey, T. M., Louis, G., Ivan, C., Alberto, S., Wilfrid, S., Douglas, M., Christopher, O., \& Justice, S. N. (2005). Validation of MODIS Active Fire Detection Products Derived from Two Algorithms, Paper No. 9. landval.gsfc.nasa.gov

Justice, C. O., Giglio, L., Korontzi, S., Owens, J., Morisette, J. T., Roy, D., Descloitres, J., Alleaume, S., Petitcolin, F., \& Kaufman, Y. (2002). The MODIS Fire Products. Remote Sensing of Environment, 83, 244-262. http://dx.doi.org/10.1016/S0034-4257(02)00076-7

Justice, C. O., Townshend, J. R. G., Vermote, E. F., Masuoka, E., Wolfe, R. E., Saleous, N., Roy, D. P., \& Morisette, J. T. (2002). An Overview of MODIS Land Data Processing and Product Status. Remote Sensing of Environment, 83, $244-262$. http://dx.doi.org/10.1016/S0034-4257(02)00076-7 
Kaufman, Y. J., Justice, C. O., Flynn, L. P., Kendall, J. D., Prins, E. M., Giglio, L., Ward, D. E., Menzel, W. P., \& Setzer, A. W. (1998). Potential Global Fire Monitoring from EOS-MODIS. Journal of Geophysical Research, 103, 32215-32238. http://dx.doi.org/10.1029/98JD01644

Louis, G., Jacques, D., Christopher, O. J., Yoram, J., Kaufman, S. N. (2003). An Enhanced Contextual Fire Detection Algorithm for MODIS, Remote Sensing of Environment, Paper No. 87. www.elsevier.com/locate/rse

Movaghati, S., Samadzadegan, F., \& Azizi, S. N. (2009). An Agent Based Algorithm for Forest Fire Detection. Journal of Applied Sciences, 9, 20. www.scialert.net

Soo, C. L., Agnes, L., \& Leong, K. K. (2005). New Methods of Active Fire Detection Using MODIS Data. Proceedings of 26th Asian Conference on Remote Sensing. www.a-a-r-s.org/acrs/proceeding/ACRS2005/Papers

Zheng, M., \& Wan, S. N. (2007). Collection-5 MODIS Land Surface Temperature Products User's Guide. 
Scientific Research Publishing (SCIRP) is one of the largest Open Access journal publishers. It is currently publishing more than 200 open access, online, peer-reviewed journals covering a wide range of academic disciplines. SCIRP serves the worldwide academic communities and contributes to the progress and application of science with its publication.

Other selected journals from SCIRP are listed as below. Submit your manuscript to us via either submit@scirp.org or Online Submission Portal.
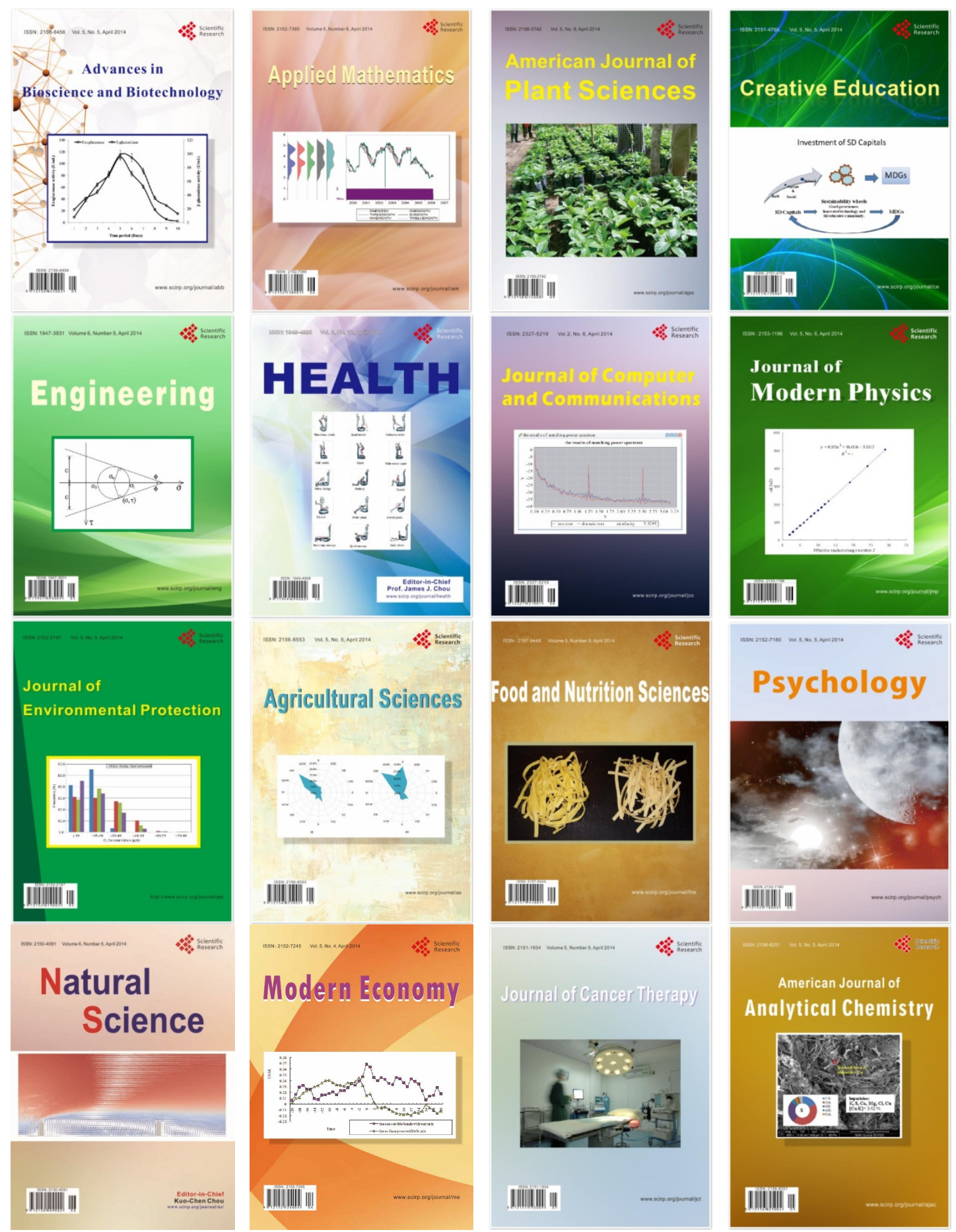